\title{
PROGNOSTIC VALUE OF PRO-ADRENOMEDULLIN, PROCALCITONIN AND C-REACTIVE PROTEIN IN COMMUNITY ACQUIRED PNEUMONIA
}

\author{
Darina Miteva, ${ }^{1}$ Yordan Radkov, ${ }^{2}$ Lilyia Ivanova, ${ }^{3}$ Trifon Chervenkov, ${ }^{4}$ \\ Vanya Kostadinova ${ }^{5}$
}

\begin{abstract}
:
Introduction: Various biomarkers are used to evaluate the severity and prognosis of community acquired pneumonia (CAP). Objectives: To study and compare the prognostic value of MR-proADM, PCT and CRP in predicting the severity and outcome of CAP.

Methods: A prospective cohort study of 92 patients hospitalized with CAP in the Clinic of Pneumology and Phthisiatrics of MHAT "Saint Marina"-Varna in 2015 was conducted. The biomarkers were measured on admission. Midregional proadrenomedullin (MR-proADM) and procalcitonin (PCT) were measured by standard ELISA, and C-reactive protein (CRP) was determined by latex-enhanced immunoturbidimetric assay. CAP severity was assessed by CURB- 65 .

Results: Patients were on average $59.2 \pm 16.8$ years of age; $68.5 \%$ of them were male. The in-hospital mortality rate was $7.6 \%$. The three biomarkers MR-proADM, PCT and CRP were significantly higher in non-survivors compared to survivors $(0.918 \pm 0.045 \mathrm{ng} / \mathrm{ml}$ vs. $0.397 \pm 0.269 \mathrm{ng} / \mathrm{ml}, \mathrm{p}<0.001 ; 2.14 \pm 0.60 \mathrm{ng} / \mathrm{ml}$ vs. $1.12 \pm 0.68 \mathrm{ng} / \mathrm{ml}, \mathrm{p}<0.001$ and $215.12 \pm 96.39 \mathrm{mg} / \mathrm{L}$ vs. $175.74 \pm 221.5 \mathrm{mg} / \mathrm{L}, \mathrm{p}<0.05$ respectively). In patients who needed intensive care, the biomarkers were also significantly higher than those in patients treated in the general hospital unit $(0.509 \pm 0.336 \mathrm{ng} / \mathrm{ml}$ vs. $0.414 \pm 0.28 \mathrm{ng} / \mathrm{ml}, \mathrm{p}<0.05 ; 1.92 \pm 0.76$ $\mathrm{ng} / \mathrm{ml}$ vs. $1.15 \pm 0.70 \mathrm{ng} / \mathrm{ml}, \mathrm{p}<0.05$ and $221.98 \pm 100.34 \mathrm{mg} / \mathrm{L}$ vs. $165.31 \pm 122.84 \mathrm{mg} / \mathrm{L}, \mathrm{p}<0.05$ resp.). MR-proADM and PCT showed a moderate correlation with the CURB-65 ( $\mathrm{r}=0.33, \mathrm{p}<0.01$ and $\mathrm{r}=0.30, \mathrm{p}<0.05$ respectively). CRP did not correlate with the CURB-65 ( $r=0.10, \mathrm{p}>0.05)$.

Conclusion: MR-proADM, PCT and CRP were significantly higher in non-survivors and in patients treated in the intensive care unit. MR-proADM and PCT showed a moderate correlation with the CURB-65, while the correlation coefficient for MR-proADM was higher. CRP did not correlate with the CURB-65.
\end{abstract}

UDC Classification: 616-01; DOI: http://dx.doi.org/10.12955/cbup.v5.1055

Keywords: MR-proADM, PCT, CRP, CAP, prognosis

\section{Introduction}

Various biomarkers are in use for evaluation of the severity and prognosis of community acquired pneumonia (CAP). Some of them, such as C-reactive protein (CRP) and, in some hospitals procalcitonin (PCT), are used routinely in clinical practice, but others, such as pro-adrenomedullin have been recently studied in an attempt to find better prognostic tools in CAP. CRP was discovered in 1930 by Tillet and Francis. It is an acute-phase protein, which is an early and sensitive, but nonspecific marker of systemic inflammation. It is synthesized mainly by hepatocytes under the influence of IL-6, IL-1 and TNF $\alpha$ (Clyne et al., 1999). Apart from its increase during infection, its level is also increased in autoimmune diseases, trauma, tissue necrosis and malignancy. PCT is the precursor of the active hormone calcitonin. It belongs to CALC-1 - gene family. It was discovered in 1975 by Moya. Its levels begin to rise within 2 hours after bacterial infection which makes it earlier marker than CRP. It reaches a peak-concentration at 12 hours and has a half-life of 24 hours (Meisner 2000). Interferon gamma, which is produced in response to viral infection, blocks PCT synthesis. Therefore, its levels do not rise in viral infections. These reasons make it a reliable marker for the etiological distinction between viral and bacterial infections and for the need of antibiotic treatment. Therefore, it would be capable of preventing antibiotic overconsumption (Christ-Crain et al., 2006). Its levels are particularly elevated in bacterial sepsis. Besides sepsis, its levels also rise in pneumonia, acute inhalation poisoning and other severe infections such as pancreatitis, appendicitis, burns, heat stroke, multiple trauma, surgeries (Becker et al., 2010).

Compared to CRP, it is a more specific marker for a bacterial infection. Adrenomedullin was first discovered in 1993 by Kitamura, and was initially isolated from pheochromocytoma (Kitamura et al., 1993). Similar to procalcitonin, it belongs to CALC-1-gene family. It is a peptide consisting of 52

\footnotetext{
${ }^{1}$ Department of Pulmonology and Allergology, Medical University in Varna, Bulgaria, dari.miteva@abv.bg

${ }^{2}$ Department of Pulmonology and Allergology, Medical University in Varna, Bulgaria, doc_radkov@mail.bg

${ }^{3}$ Department of Microbiology and Virology, Medical University in Varna, Bulgaria, liivanova@abv.bg

${ }^{4}$ Department of Medical Genetics, Medical University in Varna, Bulgaria, tuckata@gmail.com

${ }^{5}$ Department of Pulmonology and Allergology, Medical University in Varna, Bulgaria, v_vanqkostadinova@abv.bg
} 
aminoacids, mainly produced by cardiovascular tissue, but also by the adrenal medulla, lungs, kidneys, neurons. It is one of the most potent endogenous vasodilators. Its levels rise in the syndrome of systemic inflammatory response due not only to infections, but also to burns, trauma, traumatic shock, pancreatitis (Ueda et al., 1999). Its direct measurement is difficult because of its short half-life (22 minutes), due to binding to plasma proteins and technical difficulties. For practical purposes a part of the molecule of its precursor known as midregional pro-adrenomedulin (MR-proADM) is used. It has no biologically active properties, but according to its levels, the levels of adrenomeddullin can be judged. In healthy individuals, the typical values of MR-proADM are $0.10-0.64 \mathrm{nmol} / \mathrm{L}$ without difference between the sexes (Morgenthaler et al., 2005).

\section{Objectives}

To study and compare the prognostic value of MR-proADM, PCT and CRP in predicting the severity and outcome of CAP.

\section{Methods}

A prospective cohort study of 92 patients hospitalized in the Clinic of Pneumology and Phthisiatrics of MHAT "Saint Marina"- Varna in 2015 was conducted. The biomarkers were measured on admission. MR-proADM and PCT were measured by standard ELISA, and CRP was determined by latexenhanced immunoturbidimetric assay. CAP severity was assessed by CURB-65. Data were analyzed with SPSSv20.0. We used comparative and correlation analyses. Quantitative variables were reported as mean values and standard deviation (mean $\pm \mathrm{SD}$ ), and the qualitative variables were presented in number and relative proportion (\%).

\section{Results}

The patients were on average $59.2 \pm 16.8$ years of age; $63(68.5 \%)$ of them were male and $29(31.5 \%)$ were female. 22 patients $(23.9 \%)$ were treated in the intensive care unit (ICU). 7 patients $(7.6 \%)$ died during hospital stay. Characteristics of the group and the mean values of the three biomarkers are shown in Table 1.

\begin{tabular}{|ll|}
\hline Table 1: Characteristics of the studied group \\
\hline Indicator \\
\hline Average age & $59.2 \pm 16.8$ years \\
\hline Sex & 63 patients / $68.5 \%$ \\
Male & 29 patients / 31.5\% \\
Female & 22 patients / 23.9\% \\
\hline Patients in ICU & 7 patients / 7.6 \% \\
\hline In-hospital mortality rate & $8.3 \pm 4.1$ days \\
\hline Length of hospital stay & $0.437 \pm 0.293 \mathrm{ng} / \mathrm{ml}$ \\
\hline Mean value of MR-proADM & $1.19 \pm 0.72 \mathrm{ng} / \mathrm{ml}$ \\
\hline Mean value of PCT & $178.48 \pm 119.87 \mathrm{mg} / \mathrm{L}$ \\
\hline Mean value of CRP & \\
\hline Source: Authors & \\
\hline
\end{tabular}

We compared the levels of the three biomarkers in non-survivors and survivors and found out that they were significantly higher in deceased patients. MR-proADM in non-survivors was $0.918 \pm 0.045 \mathrm{ng} / \mathrm{ml}$ versus $0.397 \pm 0.269 \mathrm{ng} / \mathrm{ml}$ in survivors, $\mathrm{p}<0.001$. PCT in non-survivors was $2.14 \pm 0.60 \mathrm{ng} / \mathrm{ml}$ versus $1.12 \pm 0.68 \mathrm{ng} / \mathrm{ml}$ in survivors, $\mathrm{p}<0.001$, and CRP was $215.12 \pm 96.39 \mathrm{mg} / \mathrm{L}$ in non-survivors versus $175.74 \pm 221.5 \mathrm{mg} / \mathrm{L}$ in survivors, $\mathrm{p}<0.05$ ). Figure $1 \mathrm{a}, \mathrm{b}$ and $\mathrm{c}$

In the patients who needed intensive care, the three biomarkers were also significantly higher compared to those of the patients treated in the general hospital unit. MR-proADM in the patients treated in ICU was $0.509 \pm 0.336 \mathrm{ng} / \mathrm{ml}$ versus $0.414 \pm 0.28 \mathrm{ng} / \mathrm{ml}$ in the patients of the general hospital unit, $\mathrm{p}<0.05$. PCT in the patients treated in ICU was $1.92 \pm 0.76 \mathrm{ng} / \mathrm{ml}$ vs. $1.15 \pm 0.70 \mathrm{ng} / \mathrm{ml}$ in the patients of the general hospital unit, $\mathrm{p}<0.05$. CRP in ICU patients was $221.98 \pm 100.34 \mathrm{mg} / \mathrm{L}$ vs. $165.31 \pm 122.84 \mathrm{mg} / \mathrm{L}$ in the patients of the general hospital unit, $\mathrm{p}<0.05$. 


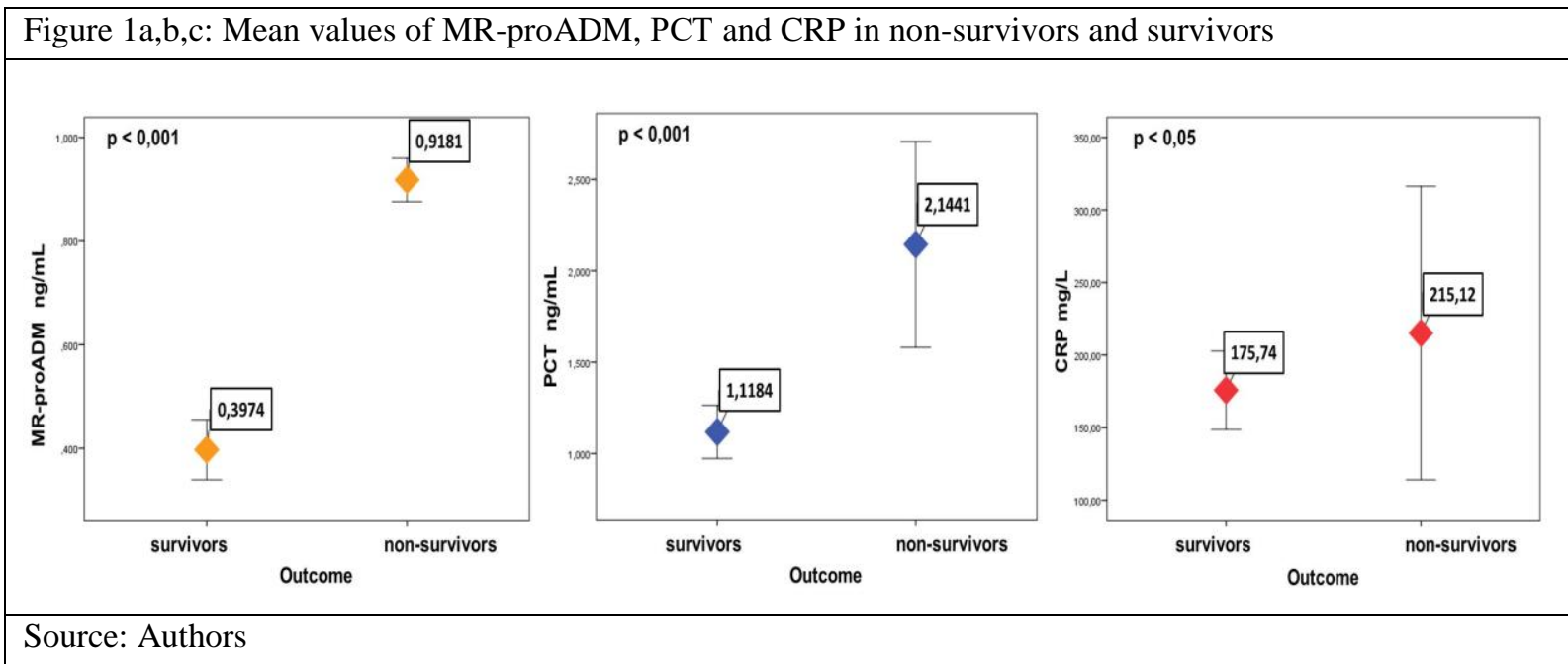

We examined the mean values of the three biomarkers in the severity groups according to CURB-65 and established that MR-proADM and PCT increased significantly with the increase of the severity of CAP. No elevation of CRP was found with the increase of the severity of CAP, assessed by the CURB-65 (see Figure $2 \mathrm{a}, \mathrm{b}$ and c). We also established that MR-proADM and PCT showed a moderate correlation with the CURB-65 score $(r=0.33, p<0.01$ and $r=0.30, p<0.05$ respectively). CRP did not correlate with the CURB-65 score $(r=0.10, p>0.05)$.

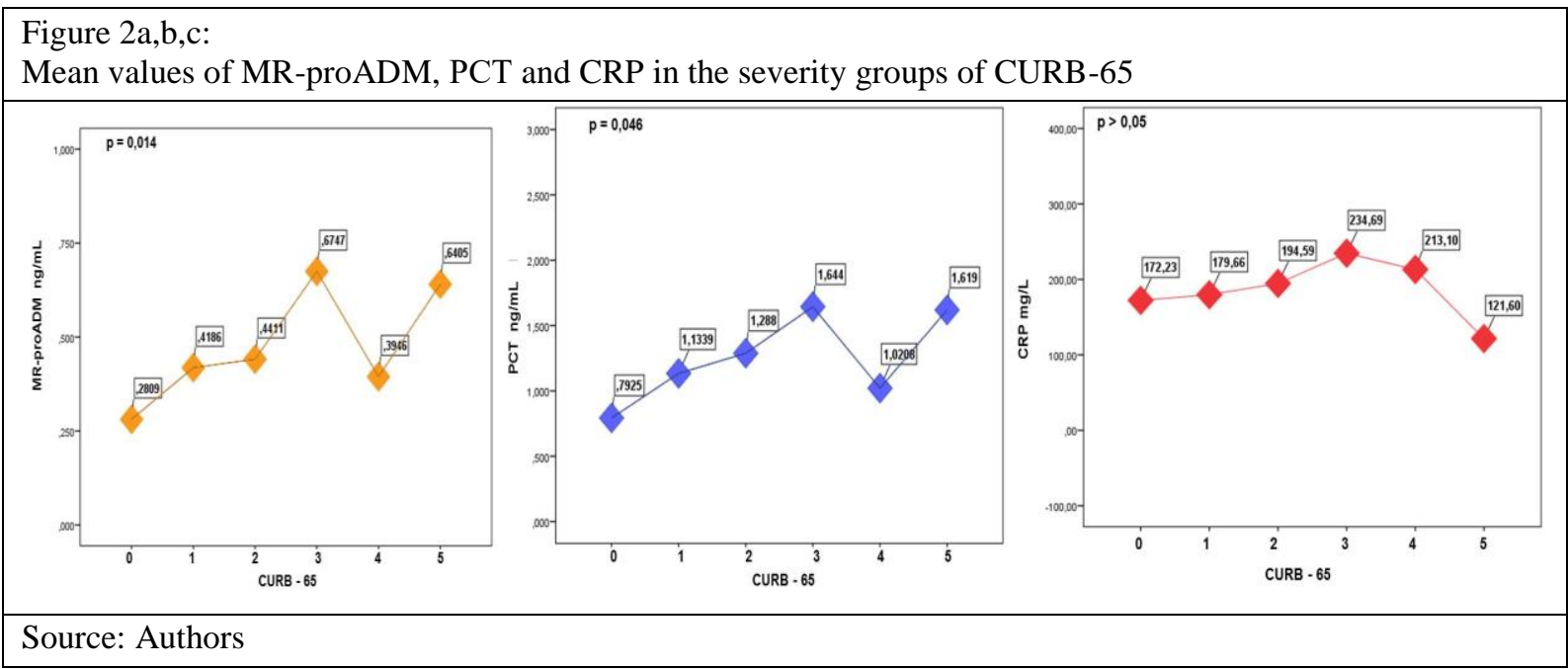

\section{Discussion}

Our study found that the levels of the three biomarkers were higher in deceased patients compared to survivors. Other authors also reported higher levels of MR-proADM in non-survivors (Christ-Crain et al., 2006; Huang et al., 2009; Suberviola et al., 2012). Higher levels of CRP and PCT in non-survivors were reported in many publications as well (Chalmers et al., 2008; Krüger et al., 2010; Menéndez et al., 2009). We think that these higher levels of the biomarkers may be linked with the more severe systemic inflammatory response of the deceased patients. We also found significantly higher values of the three biomarkers in the ICU patients. Other authors have also established the ability of MRproADM to predict the need of intensive care. Renaud et al., for example, found significantly higher values of MR-proADM in patients with severe early pneumonia (Renaud et al., 2012). PCT is also able to predict the need for intensive care (Ramírez et al., 2011). Therefore, we consider that biomarkers can be used not only as mortality predictors, but also as predictors for the need of intensive care. Our study showed an increase in MR-proADM and PCT in high-risk groups according to CURB65. Our data are consistent with the results of other authors, who have also observed such an increase in high-risk groups (Christ-Crain et al., 2006; Lacoma et al., 2014). Huang et al. established that elevated MR-proADM levels correlate with increased severity of CAP assessed by PSI (Huang et al. 2009), and Krüger, established that PCT levels increased with the severity of CAP assessed by the 
modified CRB-65 score, while there was no such increase in CRP (Krüger et al., 2008). We also did not find the elevation of CRP associated with the increase of the severity of pneumonia, as CRP did not correlate with the CURB-65 score. Therefore, we regard the other two biomarkers as better predictors of pneumonia severity compared with CRP. We found a moderate correlation of MRproADM and PCT with CURB-65. Some authors have found better coefficients of the severity scores, for example, Bello established the correlation coefficient of MR-proADM with CURB-65 to be $\mathrm{r}=0.561$ (Bello et al., 2012). We believe that the lower correlation coefficients established by us are most likely due to the relatively small number of studied patients, most of which fell into the low-risk groups according to CURB-65. This may be considered a limitation of the study. A number of authors have established a superior prognostic accuracy of MR-proADM compared with PCT (Christ-Crain et al., 2006). In our study, we have also found a slightly better correlation coefficient of MR-proADM with CURB-65 compared to that of PCT, as both markers showed moderate correlation with the severity.

\section{Conclusion}

MR-proADM, PCT and CRP were significantly higher in non-survivors and ICU patients. MRproADM and PCT showed a moderate correlation with the CURB-65, as the correlation coefficient for MR-proADM was higher. CRP did not correlate with the CURB-65. Biomarkers provide fast and reliable information to physicians about the severity and prognosis of pneumonia and can help them to take correct treatment decisions. They should therefore be included in the risk stratification of patients with CAP as predictors of severity and poor outcome.

\section{Acknowledgement}

This study is part of the project: "New biomarkers in the diagnosis and treatment of community acquired pneumonia and their role as predictors of severity and mortality of the disease" sponsored by the "Science" fund at the Medical University -Varna, Bulgaria.

\section{References}

Becker K.L, Snider R., Nylen E.S. (2010 Jan). Procalcitonin in sepsis and systemic inflammation: a harmful biomarker and a therapeutic target. Br J Pharmacol. 159(2): 253-264. doi: 10.1111/j.1476-5381.2009.00433.x

Bello S, Lasierra AB, Minchole E et al. (2012) Prognostic power of proadrenomedullin in community-acquired pneumonia is independent on etiology. Eur. Respir. J. 39: 1144-1155. DOI: 10.1183/09031936.00080411

Chalmers J,A. Singanayagam, A.Hill et al.(2008). C-Reactive Protein is an independent predictor of severity in communityacquired pneumonia, The American journal of medicine. 121, 219-225. doi: 10.1016/j.amjmed.2007.10.033.

Christ-Crain M, Morgenthaler NG, Stolz D et al. (2006). Pro-adrenomedullin to predict severity and outcome in communityacquired pneumonia Crit. Care. 10:96-103. doi: 10.1186/cc4955

Christ-Crain M, Stolz D, Bingisser R et al.(2006). Procalcitonin guidance of antibiotic therapy in community-acquired pneumonia: a randomized trial. Am. J. Respir. Crit. Care Med. 174, 84-93. DOI:10.1164/rccm.200512-1922OC

Clyne B, J.Olshaker (1999). The C-reactive protein. J. Emergency Med.17(6): 1019-1025. http://dx.doi.org/10.1016/S0736-4679(99)00135-3

Huang DT, Angus DC, Kellum JA, Pugh NA,et al.(2009 Sep). Midregional proadrenomedullin as a prognostic tool in community-acquired pneumonia. Chest. 136(3):823-31. doi: 10.1378/chest.08-1981

Kitamura K, Kangawa K, Kawamoto M,et al. (1993 Apr). Adrenomedullin: a novel hypotensive peptide isolated from human pheochromocytoma. Biochem Biophys Res Commun. 30;192(2):553-60. DOI:10.1006/bbrc.1993.1451

Krüger S, Ewig S, Kunde J et al.(2010). Assessment of inflammatory markers in patients with community-acquired pneumonia - influence of antimicrobial pre-treatment. Results from the German competence network CAPNETZ.Clin.Chim.Acta. 411, 1929-1934. DOI: 10.1016/j.cca.2010.08.004

Krüger S, Ewig S, Marre R et al.(2008 Feb) Procalcitonin predicts patients at low risk of death from community-acquired pneumonia. Eur. Respir. J. 31(2), 349-355. DOI:10.1183/09031936.00054507

Lacoma A, Bas A, Tudela P, et.al. (2014). Correlation of inflammatory and cardiovascular biomarkers with pneumonia severity scores. Enfermedades Infecciosas y Microbiología Clínica. 32 (3), 140-146.

http://dx.doi.org/10.1016/j.eimc.2013.07.006

Meisner M. (2000). Procalcitonin (PCT) - a new, innovative infection parameter. Biochemical and clinical aspects. New York: Thieme Stuttgart ISBN 3-13-105503-0.

Menéndez R, Martínez R, Reyes S et al. (2009). Biomarkers improve mortality prediction by prognostic scales in community-acquired pneumonia. Thorax. 64, 587-591. doi: 10.1136/thx.2008.105312

Morgenthaler NG, Struck J, Alonso C, Bergmann A. (2005 Oct). Measurement of Midregional Proadrenomedullin in Plasma with an Immunoluminometric Assay. Clinical Chemistry. 51 (10) ;1823-1829. DOI: 10.1373/clinchem.2005.051110 
Ramírez P, Ferrer M, Martí V et al. (2011). Inflammatory biomarkers and prediction for intensive care unit admission in severe community-acquired pneumonia. Crit. Care Med. 39, 2211-2217. doi: 10.1097/CCM.0b013e3182257445.

Renaud B, Schuetz P, Claessens YE, et al.(2012 Dec). Proadrenomedullin improves risk of early admission to ICU score for predicting early severe community-acquired pneumonia. Chest.142(6):1447-54. http://doi.org/10.1378/chest.11-2574

Suberviola B, Castellanos-Ortega A, Llorca J et al. (2012 Mar). Prognostic value of proadrenomedullin in severe sepsis and septic shock patients with community-acquired pneumonia. Swiss Med Wkly. 19;142:w13542. doi: 10.4414/smw.2012.13542.

Ueda S, Nishio K, Minamino N, Kubo A, Akai Y, Kangawa et al. (1999). Increased plasma levels of adrenomedullin in patients with systemic inflammatory response syndrome. Am J Respir Crit Care Med. 160:132-136.

DOI:10.1164/ajrccm.160.1.9810006 